\title{
Governing for and through harmonious community: The emergence of moral clinics in China
}

\begin{abstract}
In this paper, we advocate the adoption of 'more temporal and processual characters' to understand contemporary community governance in China. We show that, communities in China are seen as both producing moral problems and as being the solutions to these problems. Furthermore, we argue that the establishment of the moral clinic provides an alternative to neoliberal ways of self-governance. In the paper, we present moral clinics as a new form of community self-governance whose aim is to achieve a complex balance amongst various conflicts in the context of China's unprecedented urbanization in the name of governing for and through community harmony. Through examining the establishment of moral clinics, we expose how the relationship between the moral "hospitalization" of society and the socialization of individuals can be understood in new ways. We argue that the institutionalization of this 'moral work' is a strategy based on old techniques of Chinese traditional medicine that are being enhanced by modern organizational settings. In addition, we examine the micropolitics of the moral clinic through exposing the power relations behind its structural design, especially links with the state.
\end{abstract}

Keywords: Agglomeration/Urbanisation, Community, Governance, Local Government, Public Space, Moral Clinics , Chinese Traditional Medicine

\section{Introduction}

From September 2010, a type of volunteer organisation called the 'moral clinic' started appearing in communities in Wuxing district, Huzhou city, Zhejiang province, China. These clinics are managed and staffed by volunteer female retirees called 'moral doctors' or 'nurses.' In these moral clinics, moral doctors and nurses work together with local party organisations to 'diagnose and cure moral diseases', such as the uncivilised/immoral behaviours of residents or quarrels between neighbours in their local communities. Such incidents and behaviours are seen as 'anti-social', yet are not deemed significant enough to be considered criminal offences requiring a formal 'policing' response. Furthermore, these behaviours are often complex and not easily resolved through policing interventions.

These behaviours are either referred to the moral clinics by local residents or through introduction received from local authorities or through visits made by moral doctors and nurses 
themselves who actively seek out uncivilized behaviours in their communities. The offices of moral clinics are normally hosted in local Resident Committee buildings. Moral doctors and nurses hold surgeries twice a week, but are 'on call' to respond to issues raised by local residents or party officials. When more complex problems exist in the community, the moral clinics work together with local party officials, which facilitates processes for collectively prescribing solutions and for determining the most appropriate solutions.

In this paper, we argue that moral clinics are the benign extension of 'the party' as they are actively involved in guiding public opinion in order to promote 'healthy and civilised lifestyles' and 'harmonious relationships among neighbourhoods' in Huzhou city. We examine the context of and rationale for the establishment of moral clinics as an example of what we call 'informal community governance' in China and how the latter complements formal 'state' governance structures and strategies. We suggest that, in order to fully appreciate the distinctive impact of moral clinics on their local communities, we should adopt 'more temporal and processual characters' suggested by traditional Chinese medicine (Farquhar, 1994: 38) to understand these emergent practices of informal community governance. Incorporating this epistemological framework into analysis of community governance allows us to understand this emergent and distinctive form of governing processes that generates knowledge about particular social problems and generates bespoke interventions in the form of remedies for alleviating them. We argue that these forms of knowledge and the resultant practices and interventions that come from them are redrawing the boundaries between governing for and governing through communities.

This paper comprises eight sections. We start by examining existing literature that helps to contextualize our paper. We then present our methodology section and our strategy for analysing data. Thereafter, we critically engage with the core concepts introduced in the literature review through examining different aspects of moral clinics. As we show, moral clinics can be seen as a campaign of civilising intervention launched by the urban citizenries in response to social tensions in neighbourhoods experiencing in-migration from rural areas in China. We argue that this response involves both the medicalisation of society and socialisation of local residents. Furthermore, we argue that this response in the form of the interventions made by moral doctors and nurses in particular neighbourhoods are undertaken with the aim of creating a happy and harmonious living environment rather than simply facilitating neoliberal conditions of governance that emphasise the market as the core mechanism for social organisation. As such, in this paper, we suggest that the moral clinics provide a way of 
achieving a balanced resolution to local conflicts in the name of promoting respectful and harmonious social relationships in urban neighbourhoods in the context of China's unprecedented urbanisation.

\section{Literature Review}

We argue with Heberer and Göbel who suggest that economic reform, socio-economic transformation, rapid urbanisation and the accompanying rise in 'social mobility have significantly altered the socio-economic structure of many residential areas in China' (2011: 27). This has led to a highly mobile, increasingly pluralistic and individualised society which in the Chinese context is associated with concerns with regard to an impending moral crisis in China since the 1980s (Yan, 2011: 51). There are a number of similarities with this Chinese context and concerns about 'social problems' associated with the urbanisation of European societies centuries before. That is, the unprecedented (in terms of scale) urbanisation of Chinese society in the late twentieth and the early twenty-first century is the cause of much concern in terms of the lack of social norms and the rising 'immorality' of the new Chinese urban underclass (Turner, 2017: 938). On the whole, these concerns are associated with the recently urbanised rural migrants to Chinese cities. This phenomenon is summarized by Wan as: 'the diversifying social stratification, increasing population mobility and influx of rural-tourban migrants have brought about huge pressure for urban governance' (2015, p. 465).

In response to this crisis in the mid-1980s, the Chinese government 'launched a massive social engineering project designed to "construct" community as a new social sector that could deal with the emerging social ills caused by rapid economic growth' (Yan and Gao, 2005, p. 222; see also Bray, 2006). Through such projects the Chinese government encouraged the Chinese people 'to shoulder more responsibility, to more actively engage in market-based competition, and to assume more risks and to become more reflexive' (Kleinman et al., 2011: 14-15). As a result, former president $\mathrm{Hu}$ Jintao launched a campaign to build a 'harmonious society' (hexie shehui) in the mid 2000s (Tomba, 2009: 593). In this discourse, 'community' was seen as an important counterweight to cultural, social and political fragmentation (Bray, 2006: 531), and the promotion of harmony was advocated as a means for a peaceful relation to both nature and to fellow humans (Heberer and Göbel, 2011: 58). The underling rationality is that, the 'harmonious community' aspires to rationally integrate and reinforce the ruling capacity of the party while 'responsibilising' autonomous social players in the management of social contradictions (Tomba, 2009: 600). 
In the Western context, this kind of governing mentality and associated mobilizations in urban communities would be regarded as a neoliberal intervention that underscores 'the market as the core mechanism for social organisation' and emphasises 'the self-regulation of active and responsible individual subjects within a constructed framework of desired ethical conduct and utilises community as mechanisms for prompting and regulating civility' (Flint and Nixon, 2006: 940; see also Bannister and Kearns, 2009; Brown, 2004; Brown, 2013; Nixon and Hunter, 2009). In this context of neoliberalisation where strategies of 'informal governance' and 'soft policing activities' (Brown, 2013) are salient in urban contexts, communities have been mobilised to 'constitute a form of de-centred, locally derived governance' (Power, 2015: 247). This is what Rose refers to as 'governing through community' (Rose, 1999). Through such interventions, we can see that neoliberalism and governing through community can be closely linked.

There is a body of evidence that suggests that this form of governing through community has also become a popular strategy in contemporary China for bringing government closer to local communities and neighbourhoods (Nguyen, 2013: 228, see also Bray, 2006; Heberer and Göbel, 2011; Tomba, 2008, 2009). With this strategy, 'community' becomes a means (rather than simply a site) of governance, by which the emphasis on self-education, selfmanagement and self-improvement found in neoliberal Western contexts can also be identified in the Chinese context. We argue that in the context of the emergent appetite for governing through communities in China, and drawing on interventions often associated with the social work profession (Leung et al., 2012, p. 1045), moral doctors are becoming potentially candidates for easing these social tensions in urban contexts. Yet, as will be gradually developed in this paper, the informal community governance practices generated by moral doctors and nurses are examples of a reinvigoration of traditional social control through moral self-governance rather than a reinvention of neoliberal ways of governing.

Moreover, we also show that the practice of moral doctoring and nursing in China can be described as a 'civilising offensive' (Powell 2013: 2), whereby more powerful groups attempt to eradicate the supposedly 'uncivilised' behaviours associated with other less powerful groups. In terms of the moral doctors and nurses in Huzhou city, we argue that they have taken upon themselves "a moral obligation or an ethical duty to "civilise" or "uplift" others' (Van Ginkel, 2015), as such their work is presented as a locally delivered antidote to improve the deficiencies of 'the rural people'. We argue that moral clinics, through the twin processes of promoting self-regulation amongst the populace and using 'a demonising rhetoric 
about those who fail to regulate their behaviour in line with normalised standards' (Nixon and Hunter, 2009: 121), can be described as an attempt at purifying the social space (Bannister and Kearns, 2009: 187) in China. As such, the rationale for moral clinics is closely associated with the 'medicalisation' of so-called social problems based on a 'common-sense' morality of the middle-class (see also Brown 2004 for the case of the United Kingdom).

The notion of civility that moral doctors promote increasingly encompasses proactive volunteering and the encouragement of enhanced neighbouring (Flint and Nixon, 2006: 950). In terms of the 'hardest' or morally 'terminal' cases that are more resistant to change in Chinese neighbourhoods - just as in the United Kingdom - specifically designed interventions are introduced at the level of 'the family' or 'the vulnerable' or 'the troubled family'. 'These intensive family intervention projects have become an increasingly prominent mechanism within anti-social behaviour and social policy programmes in the UK' (Flint, 2012: 345) and, we argue, also in China. These 'troubled' family programmes can be described 'as a strategy of domestication which produces and delimits certain forms of "family life" (Turner, 2017: 933).

As well as having some similarities with contemporary 'anti-social' behaviour campaigns and 'troubled families' programmes' in the United Kingdom, the work of the moral clinics has many similarities with what were called community 'overseers' of the 'lower classes' in the 1920s in the Netherlands, who were usually females with a middle-class background who 'attempted to instil a bourgeois lifestyle - including orderliness, cleanliness, domesticity and cosiness' (Van Ginkel, 2015: 4). What these examples from the UK and Europe and also the work of moral doctors and nurses show is that the definition of "what it means to be "civilised" is . . largely defined by the middle classes' or the professional classes in these contexts (Van Ginkel, 2015: 2). In many respects, what these various movements or campaigns have in common is a response by society at large to the necessity of restoring domesticity (Turner, 2017: 934). This is associated with 'a renewed emphasis on the domestic sphere [of families] as the site for policy interventions' to tackle unaligned or anti-social behaviour (Parr, 2008: 1258).

Moreover, as we show elsewhere, "although the dominance of older women in moral clinics seems to be similar to previous mechanisms of political mobilization in the $1950 \mathrm{~s}$ in China, the practices of these older female moral doctors are different to the red armband women" (Wen et al., 2020). While older women with red armbands in 1950s were political guardians of the Maoist doctrines backed up by the threat of political power, moral doctors are 
more like pastors in the urban context. They are less repressive and more nurturing; they use their individual feminized relational capital as a governing technique; and gender played a less important role in the 1950s than in the case of moral doctors and nurses in contemporary China (Wen et al., 2020).

Furthermore, we argue that moral doctors and nurses both attempt to treat existing 'social diseases' and also prevent them from happening in the first place. In addition, the wider community services provided by the moral clinics are not only about welfare provision but also include many other social projects that local authorities expect them to deal with, many of which focus on 'promoting morality and civility' in urban neighbourhoods. Yet, as Brown rightly points out, in using urban neighbourhood organisations to promote pro-social behaviour and to demonise anti-social behaviour, there is a danger of blurring the public and the private sphere. As a consequence, the activities of moral doctors and nurses have the potential to increase the possibilities of opening up 'people's homes and private lives to surveillance' (Brown 2004: 206). In short, our study exemplifies the emergence of moral clinics: 1, as an apparatus of civilising offensive; 2 , a hybrid institutional response that entails a bricolagic piecing together of a range of aspects and fragments from a variety of conceptual frameworks, from neoliberalism, Chinese post-revolutionary consciousness and governmentalities and as a result 3 , as a form of organic urban governance by communities, for communities that involves the mobilisation of community assets in the form of skilled individuals from within the community.

\section{Methodology}

Empirical data for this study was collected through two focus group interviews and participant observation in local moral clinics in the Bilanghu and Shangxiatang shequ communities, in Huzhou city, between October 2017 and March 2018. We also held 11 informal interviews and talks with local party officials responsible for supporting moral clinics in Wuxing district. We did not conduct interviews with so-called moral patients, or beneficiaries of the clinics. This is because, unlike moral doctors and nurses who we were confident gave their genuine informed consent to participate in the study, we were less confident about their 'service users' ability to give informed cosnent (many of whom are members of vulnerable groups). There was the possibility that local officials and moral doctors acting as gatekeeps could have compelled them to participate in the study. Here, the data from interviews and participant observation are also supplemented with a critical analysis of publicity and informational materials produced by the 
moral clinics themselves, and of articles published in the local media about the work of moral clinics. All the names of participants have been anonymised.

We analysed the data through employing a thematic analysis method, recommended by Boyatzis (1998). On beginning the analysis, we created a thematic grid that generally summed up the data and allowed us to determine and gather together the opinions of our participants on the subjects explored. In terms of contextualisation, and for the purpose of attempting to draw out what is distinctive and what is similar about moral clinical interventions, we draw on examples of informal community governance of so-called anti-social behaviour from other parts of the world. We do this not to support a claim that our findings are universally valid but rather to try to present a new possibility of understanding (through the compiling of our own paradigm; see also Agamben 2005). The Chinese context is often distinctive, especially when drawing on literature and research from the global north - due to the sheer scale of Chinese society, its population level and the unprecedented scale of urbanisation.

\section{Moral work as civilisation offensive}

According to Powell, a 'civilising offensive' is a campaign whereby more powerful groups attempt to eradicate the supposedly 'uncivilised' behaviours associated with other less powerful groups (2013: 2). In the case of moral clinics, it is the moral doctors who represent a sophisticated urban professional class, and who target the rural migrants particularly living in old and less expensive communities. The following excerpt from an interview with a moral doctor, presents this relationship between the established 'local person' and the problematic behaviour of rural migrant workers:

The people who are relatively difficult to deal with are the migrant workers, who came here from all over China for work and who live in rented houses. They usually don't bag up their garbage before throwing it into the bins. I am not saying that they are morally bad; rather, it is more a problem with their living and lifestyle habits. So, I told them that you are now New Huzhou people. We are not exclusive, but you should also behave like a local person. (MD\#1)

According to this moral doctor, migrants' lifestyles are problematised in the context of an urban civilised environment. One of the moral doctors in the focus group further illustrated rural migrants' lack of integration into their new urban community:

In the past, when these peasants came to live in our community, they still retained the habit of keeping chickens. When the bird flu epidemic came, there were still 
residents feeding chickens in our community, which was very dangerous. At that time, several older women, including me, who work as moral doctors, were trying to persuade them to get rid of those chickens. I told them the outbreak of bird flu was a big threat, and that it might threaten people's lives. As people gradually begin to assimilate into our city, they are becoming more civilised. (MD\#4)

In this case, aspects of rural lifestyles are presented as putting public health at risk in the urban context. Thus, refraining from certain rural habits (e.g. keeping chickens, growing vegetables in public areas etc.) is a sign that rural migrants, whom our participants often referred to as 'peasants', are becoming integrated and more civilised. Furthermore, the populations of urban residential areas in Chinese cities are in flux as a consequence of the processes of marketisation and rapid urbanisation, and as a result, the populations of some of these more transitional urban neighbourhoods are becoming increasingly heterogenous (Herberer, 2009: 492). According to our focus group participants and interviewees, this is especially the case in older, less expensive and more 'transitional' residential neighbourhoods in Huzhou. It is in this context that the first moral clinics were established to promote 'the suzhi (quality) of the population and the strengthening of the nation' (Tomba 2009: 592). In this context, we suggest that the moral clinics in Huzhou city are the latest example of this wider 'civilising project' in China, which is in response to the changing demography of urban population in China as a consequence of rural-urban migration.

Increasing diversity in urban neighbourhoods is seen as threat to social cohesion in these urban neighbourhoods. The primary source of these problems is the alleged uncivil behaviours of rural migrants. It is in this context that the moral clinics emerged and were supported by the local branches of the community party. Rather than relying on disciplinary and punitive measures, the approach that the moral clinics have adopted, as we will show below, is that of community management 'by negotiation', where these 'doctors' behave less like police and more like 'arbiters of lifestyles' (Flint, 2012: 824). We argue that the moral clinics are making explicit the often-implicit behavioural expectations of the 'urban' citizenry in China. In many ways, this involves what Millie calls the politics of moral and behavioural improvement through the process of the 'othering' of a 'disrespectful' minority (2009: 13).

In this context, as moral doctors are themselves residents of these neighbourhoods, the formation of moral clinics as a public space is also a deliberate attempt to de-anonymise urban social space and to promote opportunities for social encounters and for building an enhanced sense of community. As a moral doctor in one of the focus groups further explained, 
We encourage everyone (doctors and nurses) to step out of their small family and integrate into the big family (the community). If the residents get familiar with each other through the activities we organise, the conflicts will be easier to solve. At the same time, the purpose of our activities is also to enable everyone living in the community to understand and support the work of the moral clinic. (MD\#4)

In turn, it is through the process of 'stepping out' that the social problems that exist in the urban social space and the so-called morally 'problematic' behaviours of citizens become increasingly visible. These kinds of tension and the associated civilising practices can also be seen in the United Kingdom's governance of anti-social behaviours. As Bannister and Kearns argue, there is an increasing intolerance of the behaviours of 'others' especially their behaviours in public spaces (2009: 173). This intolerance has become associated with an appetite for targeted interventions by communities in the absence of official or effective agencies of regulation (Bannister and Kearns, 2009: 183). In this sense, a 'civilising offensive' seems to be operative both in the Western and Chinese contexts in the era of neoliberalisation. In terms of the moral doctors in Huzhou city, we argue that they have taken upon themselves 'a moral obligation or an ethical duty to "civilise" or "uplift" others' (Van Ginkel, 2015). Moral clinics are presented as a locally delivered antidote to improve the deficiencies of 'the rural people'. We argue that moral clinics, through the twin processes of promoting self-regulation amongst the populace and using 'a demonising rhetoric about those who fail to regulate their behaviour in line with normalised standards' (Nixon and Hunter, 2009: 121), can be described as an attempt at purifying social spaces (Bannister and Kearns, 2009: 187) in China.

The role of and even the name 'moral clinic' have come under criticism in the local press in Huzhou city due to these organisations' tendency to stigmatise particular group of residents presented as negative and pathological (Pow, 2007: 1541) and who, in turn, are targeted for disciplinary intervention. A moral doctor addressed this aspect of the clinics' work in one of our focus groups:

To be honest, this name, 'moral clinic', has an element of misrepresentation to it. It implies the people whom we treat are immoral. There was one reporter who criticised the name 'moral clinic' and argued that morality should not be treated ... Some people do not like the name moral clinic, because the words clinic, doctor and nurse always remind people of diseases. (MD\#8) 
Despite these critical reflections on how the work of the moral clinics might be perceived in local communities, the work of moral doctors and nurses continues to be supported by officials from the local communist party - precisely because they are able to deal with problems, conflicts and issues that are out with the bandwidth of formal agencies, such as the police and social workers._As such, the work of moral clinics can be described as an example of what Cohen refers to as a 'more mesh thinning than net widening' (cited in Brown, 2004: 209). That is, "people and behaviour that have previously been in the net but slipped through are now being caught.' (Brown, 2004: 209). As well as the 'mesh thinning' capture of cases referred to the moral clinics and through their mobile work in communities, there are also some 'net widening' activities that increase the moral clinics' surveillant reach into communities, including into schools, as seen in the following example:

We have set up a team that is called Eagle Guardians, who are composed of elementary and middle school students who live in our community. We invite them to assist us in our daily work. Moreover, our service in the Shangxiatang community has been extended to Xinfeng Primary School. The clinic functions as a bridge that connects the school and the community, so as to provide moral education to and conduct moral supervision of primary school students. This is because some issues should start with students. For example, some students just moved into the city with their grandparents from rural areas, and there needs to be a process for them to integrate into their new context. (MD\#13)

Furthermore, as well as 'mesh thinning' and 'net widening,' moral doctors' adoption of the model of Chinese traditional medicine (especially in the process of conflict solving in urban communities) has facilitated the emergence of new working practices through the institutionalising of moral work that goes beyond the discourse of neoliberal governance, as we show in the following sections.

'Medicalisation' of society and the socialisation of residents through moral practitioners

In China, just as in Europe, there are many indigenous forms of expertise for selfmanagement, derived from earlier periods (Rose, 2011: 255). The techniques of Chinese medicine and the role played by elderly female local healers is such an example. The moral clinic provides a platform for what we describe below as interventions by 'warm-hearted' elderly females in the ongoing 'construction of civilisation'. One of local officials we interviewed was explicit about how we saw the work of older female moral doctors in Huzhou: 
We believe that no matter in which community in which period, there will be a group of people who are keen on public welfare... That is why we have set up a moral clinic. Let these warm-hearted old ladies make their own contributions to our construction of civilisation. (Official\#1)

We find that the institutionalisation of this moral work is a strategy wherein some of the traditional techniques of Chinese medicine (in particular, its distinct ways of healing) have been reactivated and made more efficient through reinterpreting them within modern organisational settings. That is, like practitioners of Chinese medicine, moral doctors attempt to heal 'in a world of unceasing transformation' (Farquhar, 1994: 24). Although the organisational structure of the moral clinics is expected to take a standard form, the actual practices of the moral practitioners (doctors and nurses) are nuanced, responsive and tailored to the needs of the individual. That is, the techniques and approaches of the moral doctors are rarely standardised. They involve effective combinations of subtle, resourceful and emotionally intelligent interventions.

We argue that traditional Chinese medicine is one of the multifaceted tactics involved in the art of community governance through moral clinics in Huzhou (see Wen et al., 2020). The reason for this is, just as in the experiential interventions associated with traditional Chinese medicine, the moral clinic gives rise to analytics in and of the specific, the contingent and the experiential. Furthermore, both have in common a way of knowing the world that 'works by metaphors and analogies rather than deductions and inductions' (Zhan, 2014: 258). As such, moral doctoring functions as a central charter of urban moral governance with an emphasis on the healing of the moral ills of the community, which is analogous to the healing of the physical ills of the individual human body.

Through their role as defenders of harmony within their communities, moral doctors and nurses use their local knowledge and accumulated personal and professional skills (that is, their expertise) to diagnose and assess the issues in their local communities that they consider uncivil and that, as such, could be injurious to the social body. 'Diagnosis' here can be understood as 'the precise detention and definition of an illness afflicting the social organism, while the clinical notion of 'health' serves as a standard for the evolution of abnormal symptoms' (Honneth, 2014: 34), which is defined precisely by the behaviours exemplified by these moral doctors, who are also moral exemplars. As such, the moral clinics are a part of a strategy aimed at preserving the moral make-up of the population (Rose, 2011: 240). 
In the framework of Elias (1939/2000)' civilising process, this civilising offensive also adds a new ingredient, namely the element of 'peer socialisation' by active, conscious and deliberate powerful groups (Powell, 2013: 5). In the case of moral clinics, the medicalization of society is thus accompanied and fulfilled by the socialization of peers. Moral doctors and nurses 'relate to others as human beings, demonstrate attentiveness to their diverse needs, and take responsibility for addressing those needs in specific contexts' (Bond-Taylor, 2017: 139). This micro-practice of routinising appropriate behaviours is an attempt to instil order in the spatial practices of all individuals in these urban neighbourhoods.

In order to be able to fulfil their tasks, moral doctors and nurses are generally retired professional women who are party members, but were formerly cadres or teachers who are seen as reliable, responsible, self-disciplined, 'high-quality' citizens, who exemplify 'the emergence of new subjects, who serve the goal of the "community cultivation" project' (Tomba, 2009: 605). Like practitioners of traditional Chinese medicine, moral doctors can be effective because they are the embodiment of 'good life experience' (Farquhar, 1994: 11). They are residents with a reputation for being committed citizens and who continue to lead a simple yet effective life in the neighbourhood, focusing on community service in Chinese urban settings. They have been specially selected because of their professional skills and experiences, and also their moral capitals as respected, long-term members of communities.

Furthermore, their extensive personal and professional experiences are combined with a highly flexible and responsive (non-standardised) 'treatment' regime through their interventions in local communities. They must know how to employ an array of 'local', 'traditional' and also professional skills and resources to manage communities based on the norms of common-sense everyday living (Farquhar, 2012: 160). This was explained to us by a moral nurse:

Different methods should be applied in different situations by different doctors. Thus, they need to creatively choose methods in order to communicate and solve problems effectively. This is because people who come to us usually vary a lot, and that means they have to be treated in individual ways. So, we have also learned a lot during our prescribing process by talking to different people. There is no single method of solving all the problems. Moral doctors and moral nurses need to adopt tailored methods. (MN\#1) 
In this sense, moral doctors are caseworkers who rely to a great extent on their communication and leadership skills in their face-to-face interactions with citizens (Read, 2000: 817). Creativity or innovation is just as important as intimacy and familiarity in the operational effectiveness of the moral clinics. As the 'clinical' encounter in these clinics both draws on and generates knowledge about particular problems, it involves training doctors in the rational use of proven methods while allowing, even demanding, that they intervene creatively in the ever-new challenges of (moral) illness (Farquhar, 1994: 2). In this sense, to be creative thus requires deep experience and the distilling of best practices. Therefore, the experience accumulated by mature women in their personal and professional lives becomes an asset. Their age, maturity and stage of life become their comparative advantage. Their life experience (jingyan) comes from their wisdom and the cultivation of skills through a slow process whereby they develop adeptness at dealing with other people (Farquhar, 1994: 226). In short, their wisdom, ethical character and informal neighbourly demeanour enhance their ability to facilitate effective mediation that is both in their patient's best interest and also in the interest of the neighbourhood as a whole.

Governing through community

In contemporary China, as in the United Kingdom, a defining element of current 'civilising processes' involves the increasing self-governance of behaviour and conduct. This places not just individuals but also neighbourhoods and communities at the forefront of these processes, as Flint and Nixon explain:

governing conduct is the emergence of the neighbourhood as the site in which civility is to be enacted and regulated, resulting in an increasing role for 'communities' in defining, surveying and reporting incivility and a redefining of required civility to encompass proactive acts of citizenship arising from duties and obligations to others (2006: 950).

In this context, the individual body of targeted patients in the public area 'becomes the very site through which civilised order is both undone and regenerated through extensive disciplinary and pedagogical intervention' (Turner, 2017: 934). Thus, in the process of community building, in the face of mounting pressure to resolve social tensions, the moral clinics can be seen as a means whereby the Chinese government 'seeks to move away from a model based on direct government towards a model of structured self-governance' (Nguyen, 2013: 213). 
Indeed, the introduction of moral clinics is a relevant example of governing through community, as a local official explains:

The moral clinic acts as a new carrier to strengthen the moral construction of all citizens. This is undoubtedly a new step towards mobilising the sense of ownership and the enthusiasm of community residents. Through moral hospitals and clinics in the community, the residents' sense of ownership and enthusiasm are mobilised, and the people are guided towards self-education, selfmanagement and self-improvement. It also effectively elevates residents' moral levels and civilised qualities, and as a result creates a happy and harmonious living environment. (Official\#2)

From the perspective of this official, the moral clinic can be located in the current neoliberal context in China. Yet, as we discuss below in the paper, the governing strategy of moral clinics is more a reinvigoration of Chinese traditional social control mechanisms through 'moral selfgovernance' than it is an introduction of neoliberal ways of governing.

As we can see in the statement made by a moral doctor below, the mission of the moral clinics also includes aspects of communitarianism, which are combined with neoliberal aspirations to support economic development:

The moral construction of citizens is associated with our national rejuvenation, national development, social progress and people's well-being. It is an important task to build a harmonious society and an important guarantee for sound and rapid economic development in society. At present, in an era with diversified social values, various ideas and complicated concepts, moral construction plays an increasingly important role in guiding ideology and promoting social harmony. (MD\#5)

In this regard, the establishment of moral clinics provides a diverse blend of ideologies to represent a means of governing for harmony through the community. In the local communities in Huzhou city, moral doctors attempt to strike a balance between 'progressive collectivism', which emphasises the improvement of certain conditions in urban society, and "progressive individualism', which emphasises improvement of the self. This is an art of governance that is concerned not only with the management of conduct at the level of individuals and communities but also with the optimisation of the relationship between state government and 
self-government. In this context, 'social harmony' is to be achieved through community governance and citizen moral education. This relationship is described by an official:

[With moral clinics], we achieved the organic combination between community governance and citizen moral education. Community, as a settlement for urban residents, accommodates people of different ages and occupations, which causes many problems and disputes among them. To this end, community party committees of the district fully exert their functions, while the community moral clinic also gives full play to the self-education and self-management of community residents, coordinates community neighbourhoods and provides residents with a platform for mutual restraint and consultation. (Official\#3)

The remarks above reflect the articulation of a symbiotic relationship between the agencies of the state and the moral clinics, with the latter attempting to achieve the simultaneous promotion of the enhancement of the 'moral quality' of the citizenry and of increasing self-governance within the community (Nguyen, 2013: 221). In this sense, the establishment of moral clinics is an example of a community governing itself through a process aimed at enhancing the levels of social harmony in communities.

Moreover, the establishment of a network of moral clinics can be understood as a purposeful strategy for attempting to guide morality and for promoting social harmony rather than fashioning communist subjectivities per se. As a moral doctor informed us:

The moral clinic is not only a non-governmental organisation but also an effective carrier for moral construction. It was innovated by the masses, so it must be rooted in the masses and must continuously expand its popularity and influence among them through strengthening publicity and improving the effectiveness of the work of the moral clinic. (MD\#7)

The moral clinics' bottom-up (born of the community) origins involve a more nuanced and iterative process, with the aims of the moral doctors being the gradual transformation of 'uncivilised' behaviours into more civilised behaviours. The ultimate objective of these processes, according to the moral doctors is the promotion of a self-governing and responsibilised citizenry, for example:

Through our work, citizens in communities will gradually change from passively accepting supervision and persuasion to actively self-monitoring, and they will strengthen their moral awareness subjectively and resist bad behaviour that is 
contrary to civilised morality. This is key to exploring a path for the citizens, to transform from being morally constrained by others to becoming morally selfdisciplined. (MD\#5)

Yet, the power of moral clinics to effect change and civilise behaviour has its limitations. In the following statement from an interview, a moral nurse shed some light on the complexity of community issues they try to deal with:

Initially, I thought that the moral clinic could only help people solve problems in families. We are now doing other work. For example, we assisted the residents' committees in persuading several stubborn tenants to agree to move out. We went to restaurants to solve the problem of fume extraction and so forth. However, there are difficult situations involved in addressing these trivial things. There are some morally 'terminal' or incurable patients. (MN\#3)

In terms of the 'hardest' or morally 'terminal' cases that are more resistant to change in Huzhou neighbourhoods - just as in the United Kingdom - specifically designed interventions are introduced at the level of 'the family' or 'the vulnerable' or 'the troubled family'. Moreover, despite appreciating the limitations on their ability to effect change amongst some cohorts in their communities, moral doctors are generally optimistic about their proactive and preventive work, that is, especially the work they do that they think will prevent problems from happening in the first place.

Commentary on self-governing in China: moving beyond neoliberalism

We argue that the world of the moral clinics in Huzhou city is an example of governing through community which is made possible through utilizing moral nobility of older Chinese women in subtle forms of governance, which entails the combination of uses of humility, empathy and an ethics of care (see Wen et al., 2020). As we discuss below, while moral clinics may share many characteristics of neoliberal governance in terms of the role that communities are intended to play in governing residents, their underlying rationales are different.

As Bloom argues, neoliberalism is as much an ethico-political project as it is an economic one (2017: 5). Just as markets are seen to be the best source for their own management, so too are individuals. This ethos of limited government and private governance means that responsibilities of the state are transferred to social actors (Peeters, 2019: 51). As such, responsibilisation is the key to the analysis of neoliberalism. Yet, as Peeters argues, in the case of "responsibilisation as "the construction of civility" (such as the case of moral 
clinics, which we examine in this paper, or what Rose referred to as 'ethical reconstruction'), this is beyond a strictly neoliberal interpretation of responsibilisation (2019: 55).

Responsibilisation is 'not necessarily a simple transfer of tasks from state to social actors. It can also imply the construction of responsibility where it does not exist yet' (Peeters, 2019: 55). In other words, responsibilisation can work for the construction of civility, yet the construction of civility does not necessarily require neoliberal responsibilisation. This is particularly true in the case examined here, where targeted citizens are rural migrants who have yet to be subjected to the expectations of 'urban' socialisation, and as such, they lack a sense of urban civilisation and their lifestyles are presented as a threat to public orders and health in the urban context. Moreover, as noted above, the work of moral doctors concerns not only welfare provision through self-governing but also the 'promoting [of] morality and civility' amongst community residents.

Secondly, the "neoliberal narrative reflect[s] an ethic of "justice" through its focus on universalist, legalistic approaches to imposing responsibilities upon families' and individuals (Bond-Taylor, 2017: 135). By advocating this ethic of 'justice', neoliberal governance often 'seeks to create a distance between authorities and actors by sustaining a market and reshaping the forms of economic exchanges based on contracts' (Rose and Miller, 2010: 297). Consequently, neoliberal community self-governance prompts a contractualisation of 'neighbourhood relations and a corresponding decline in socially inflected relations' (Power, 2015: 248), thus prompting depersonalised and legalistic neighbouring (Power, 2015: 258), and as a consequence, this can result in the diminishing of people's capacity for affective interactions with others.

Yet, unlike the contractual arrangements for support in the 'Troubled Families' programme in the United Kingdom that 'is founded in the liberal notion of free and equal parties making fair exchange of terms for mutual benefit' (Bond-Taylor, 2017: 135-136), these elderly female moral doctors in China demonstrate a feminist ethics of care through the building up of (rather than the diminishing of) personal affects (as opposed to a kind of marketised contract) between moral workers and community members. Like practitioners of traditional Chinese medicine, moral doctors' measurements of success focus on the capabilities of providing 'a holistic and creative, reflexive and responsive solution' (Parr, 2008: 1269) and the relational capacities of providing services to identify and respond to people's needs (BondTaylor, 2017: 139),_rather than narrow, short-term focused, neoliberal managerialist assessments of effectiveness (Parr, 2008: 1256). 
Thirdly, although moral doctors' roles are indeed influenced by neoliberal aspirations in the context of endemic neoliberal inflections (Rofel, 2007: 5), they reflect a Chinese 'postrevolutionary' womanhood which remains firmly committed to the collective cause. Thus, similar to what Zhang (2018: 45) argues, what is emerging in China is not a usual 'neoliberalism' story of self-advancement but a more complicated picture based on assemblages. Moral doctors and nurses have transformed this collective cause from the Maoist ethics of serving the people into an ethic of promoting harmony, civility and community in these fast-changing urban contexts. Thus, what we have observed in China is not the adoption of 'a seamless totality called neoliberalism'. Rather, it is the piecing together of disparate experiences in the process of the Chinese people attempting to remake themselves (Rofel, 2007: 12). That is to say, rather than being explicitly neoliberal in motivation, which stresses a 'progressive individualism' aimed at the governing of the self, the mission and practice of the moral doctors also promotes 'progressive collectivism', which aims at improving the conditions of urban society as a whole in the process of community building. With progressive collectivism, the community or, more accurately, community members are expected to work together to create a happy and harmonious living environment. In turn, the ethical community of which the moral doctors and nurses are exemplars, is expected to have a stabilising_effect in the context of the fast-changing material environment and associated population churn through the organic combination of community governance and the moral education of citizens.

\section{Conclusion}

The emergence of moral clinics in Huzhou city is very much an urban phenomenon associated with unprecedented rural-to-urban migration in China and in the context of the social-political concerns about morality and civility. Just as in the social transitions including the urbanization of European societies in recent centuries, concerns about the moral health of the nation comes to focus on the behaviours and practices of particular newly arrived groups in cities. In China, these concerns have been articulated around the behaviours and practices of rural migrants in public and social spaces, including the growing of vegetables in public spaces, the keeping of poultry etc. in apartment blocks and balconies. These social problems are nuanced, trivial and varied, and therefore cannot be easily solved through the usual standardised formal methods of policing and social work. Thus, finding alternative approaches becomes necessary in order to address community issues that are neither clearly defined nor straightforward. This is precisely the niche that moral clinics are trying to fill. 
The moral clinics are a hybrid institutional response to these issues in China, in that they are an organic, bottom-up phenomena that has emerged in response to urban neighbourhood and community needs - yet they have also been enabled and supported by local communist party officials. As such the hybridity of their emergence and enablement is of considerable interest - as is the sophisticated mission they have created for themselves in this urban context as the facilitator of individual and collective progressivism. We refer to this as being sophisticated - because it entails a bricolagic piecing together of a range of aspects and fragments from a variety of conceptual frameworks, from neoliberalism, Chinese postrevolutionary consciousness and governmentalities - as such we envision this article to be of considerable interest to a variety of urban studies specialist across numerous disciplines.

It should also be noted that the work of moral clinics targets not only those 'moral patients' whose behaviour impacts negatively on their neighbours or families but also those negatively impacted by those actions. In other words, moral clinics attempt both to 'cure' moral patients and to 'heal' victims. The moral clinic thus becomes a halfway point between institutional mobilisation and socialisation. In many ways, what the moral clinic represents is a form of organic urban governance by communities, for communities that involves the mobilisation of community assets in the form of skilled individuals from within the community (rather than external agents, such as police and social workers) to deal with the communities' own problems - and in the process to inspire Community Action and Community Development amongst residents. With the addition of an inter-generational component to the work of the moral clinics through the Eagle Guardian programme in schools in Huzhou, we are further witnessing a process of intergenerational transfer of (1) skills from older moral doctors and nurses to the young Eagle Guardians, and (2) the transfer of knowledge from the young Eagle Guardians to their rural migrant parents and grandparents at home.

Last, since all of this is being implemented by groups of elderly women, we consider this to be of considerable interest, and well-worth the attention of researchers in the field of urban studies. These older women are leading the vanguard of governance through community in urban settings in China - and they are doing it in a way that recognizes, enables, and facilitates what they present to be their unique skill set which have been accumulated over their lives - and which are central to the modus operandi of the moral clinics - a subtle, warm-heated range of bespoke interventions for responding to what the moral doctors and nurses see as acute social issues that are detrimentally impacting on the urban neighbourhoods they are part of. As such, the moral clinics are an innovative phenomena that places older people, especially older 
women as active campaigners against (rather than victims of) what they perceive to be the major social problems impacting on their communities, and as such we hope researchers focusing on emergent, organic forms of community interventions in urban spaces from across the world will be interested in our research - as it could be seen as an example of a community trying to take action to rebuild itself from the inside out. 


\section{References}

Agamben G (2005) The Time That Remains: A Commentary on the Letter to the Romans. Palo Alto, CA: Stanford University Press.

Bannister J and Kearns A (2009) Tolerance, respect and civility amid changing cities. In: Millie A (ed.) Securing Respect: Behavioural Expectations and Anti-Social Behaviour in the UK. Bristol: Policy Press, pp.171-192.

Bloom P (2017) The Ethics of Neoliberalism: The Business of Making Capitalism Moral. New York and London: Routledge.

Bond-Taylor S (2017) Tracing an ethic of care in the policy and practice of the Troubled Families Programme. Social Policy and Society 16(1): 131-141.

Boyatzis RE (1998) Transforming Qualitative Information: Thematic Analysis and Code Development. London: SAGE.

Bray D (2006) Building 'community': New strategies of governance in urban China. Economy and Society 35(4): 530-549.

Brown AP (2004) Anti-social behaviour, crime control and social control. The Howard Journal of Criminal Justice 43(2): 203-211.

Brown DM (2013) Young people, anti-social behaviour and public space: the role of community wardens in policing the 'ASBO generation'. Urban Studies 50(3): $538-555$.

Elias N (2000) The Civilizing Process: Sociogenetic and Psychogenetic Investigations. Oxford: Blackwell. (Original work published 1939).

Farquhar J (1994) Knowing Practice: The Clinical Encounter of Chinese Medicine. Boulder, CO: Westview Press.

Farquhar J (2012) Knowledge in translation: Global science, local things. In: $\quad$ Levine $\quad \mathrm{S}$ (ed.) Medicine and the Politics of Knowledge. Cape Town: Human Sciences Research Council Press, pp.153-170).

Flint, J (2012) The inspection house and neglected dynamics of governance: the case of domestic visits in family intervention projects. Housing Studies 27(6): 822838. 
Flint J and Nixon J (2006) Governing neighbours: Anti-social behaviour orders and new forms of regulating conduct in the UK. Urban Studies 43(5-6): 939-955.

Gilligan C (1982) In a Different Voice: Psychological Theory and Women's Development. Cambridge, MA, and London: Harvard University Press.

Heberer T (2009) Evolvement of citizenship in urban China or authoritarian communitarianism? Neighborhood development, community participation, and autonomy. Journal of Contemporary China 18(61): 491-515.

Heberer T and Göbel C (2011) The Politics of Community Building in Urban China. London: Routledge.

Honneth A (2014) Disrespect: The Normative Foundations of Critical Theory. Hoboken, NJ: John Wiley \& Sons.

Kleinman A, Yan Y, Jun J, Lee S, and Zhang E (2011) Deep China: The Moral Life of the Person. Berkeley: University of California Press.

Millie A (2009) Introduction. In: Millie A (ed.) Securing Respect: Behavioural Expectations and Anti-Social Behaviour in the UK. Bristol: Policy Press, pp.1- 20.

Nguyen T (2013) Governing through Shequ/community: The Shanghai example. International Journal of China Studies 4(2): 213-231.

Nixon J and Hunter C (2009) Disciplining women: anti-social behaviour and the governance of conduct. In: Millie A (ed.) Securing Respect: Behavioural Expectations and Anti-Social Behaviour in the UK. Bristol: Policy Press, pp. $119-138$.

Parr S (2008) Family intervention projects: A site of social work practice. British Journal of Social Work 39(7): 1256-1273.

Peeters R (2019) Manufacturing responsibility: The governmentality of behavioural power in social policies. Social Policy and Society 18(1): 51-65.

Pow CP (2007) Securing the 'civilised' enclaves: Gated communities and the moral geographies of exclusion in (post-)socialist Shanghai. Urban Studies 44(8): $1539-1558$.

Powell R (2013) The theoretical concept of the 'civilising offensive' (Beschavingsoffensief): Notes on its origins and uses. Human Figurations 2(2). 
Power ER (2015) Placing community self-governance: Building materialities, nuisance noise and neighbouring in self-governing communities. Urban Studies 52(2): 245-260.

Read BL (2000) Revitalizing the State's urban 'nerve tips'. The China Quarterly 163: 806-820.

Rofel L (2007) Desiring China: Experiments in Neoliberalism, Sexuality, and Public Culture. Durham, NC: Duke University Press.

Rose N (1999) Powers of Freedom: Reframing Political Thought. Cambridge: Cambridge University Press.

Rose N (2011) Biological citizenship and its forms. In: Zhang E, Kleinman A, and Tu W (eds) Governance of Life in Chinese Moral Experience: The Quest for an Adequate Life. London: Routledge, pp.237-265.

Rose N and Miller P (2010) Political power beyond the State: Problematics of government. The British Journal of Sociology 1(61): 271-303.

Schlosser JA (2008) Issues in interviewing inmates: Navigating the methodological landmines of prison research, Qualitative Inquiry 14(8): 1500-25.

Tomba L (2008) Making neighbourhoods: The government of social change in China's cities. China Perspectives 76: 48-61.

Tomba L (2009) Of quality, harmony, and community: Civilization and the middle class in urban China. Positions: East Asia Cultures Critique 17(3): 591-616.

Turner J (2017) Domesticating the 'troubled family': Racialised sexuality and the postcolonial governance of family life in the UK. Environment and planning D: Society and Space 35(5): 933-950.

Van Ginkel R (2015) Containing the urban poor-coercion or consent? Disciplining missions and civilising offensives in the Netherlands. Human Figurations 4(1).

Yan Y (2003) Private Life under Socialism: Love, Intimacy, and Family Change in a Chinese Village, 1949-1999. Palo Alto, CA: Stanford University Press.

Yan Y (2011) The changing moral landscape. In: Kleinman et al. Deep China: The Moral Life of the Person. Berkeley: University of California Press.

Zhan M (2014) The empirical as conceptual: Transdisciplinary engagements with an 'experiential medicine'. Science, Technology, \& Human Values 39(2): 236-263. 
Zhang, L. (2018). Cultivating the therapeutic self in China. Medical anthropology, $37(1), 45-58$.

Wen, M., Zhang, S., \& McGhee, D. (2020). Utilizing the moral nobility of older Chinese women in governance: The uses of humility, empathy, and an ethics of care in moral clinics in Huzhou city. The British Journal of Sociology, 71(2), $300-313$ 